\title{
Lipoprotein (a) as an independent risk factor for myocardial infarction in patients with common hypercholesterolaemia
}

\author{
G F Watts, E M Kearney, N A Taub, B M Slavin
}

\begin{abstract}
Aims: To examine whether lipoprotein (a) ( $L p(a)$ ) increases the risk of myocardial infarction (MI) in patients with common hypercholesterolaemia.

Methods: 15 middle aged men with common hypercholesterolaemia (mean serum low density lipoprotein (LDL) cholesterol 4.94 mmolih, SD 1.0) and a history of $\mathrm{MI}$ were selected consecutively from referrals to a lipid clinic. A control group that had not sustained an MI and with similar age, sex, cigarette smoking and blood pressure characteristics was also selected from the same clinic. Serum cholesterol, triglyceride, LDL cholesterol, high density lipoprotein cholesterol, apolipoproteins $\mathbf{A I}$ and $\mathbf{B}$ and $L p(a)$ were measured in both groups. Lp(a) was assayed by immunoturbidity.

Results: The serum concentration of Lp(a) was significantly higher in patients with MI (geometric mean 0.64 (95\% confidence interval 0.36 to 1.14$) v 0.30$ $(0.21$ to 0.42$) g / 1, p=0.02)$, but there were no significant differences in other variables. Stepwise logistic regression analysis showed that $L p(a)$ was the only significant predictor of MI $(p<0.02)$. The odds ratio of $M I$ (adjusted for age, smoking, blood pressure and apolipoprotein B) for an $L p(a)$ of $>0.57 \mathrm{~g} / 1$ was $16 \cdot 5,95 \%$ confidence interval $2 \cdot 3$ to $125 \cdot 4$ $(\mathbf{p}=\mathbf{0 . 0 0 1})$.

Conclusion: In middle aged men with common hypercholesterolaemia the serum concentration of $L p(a)$ is a powerful and independent risk factor for $M I$. Lp(a) should probably be routinely measured in all patients referred to a lipid clinic.
\end{abstract}

(F Clin Pathol 1993;46:267-270)

\author{
Department of \\ Endocrinology and \\ Chemical Pathology \\ (UMDS), St Thomas's \\ Hospital, London \\ SE1 7 EH \\ G F Watts \\ E M Kearney \\ B M Slavin \\ Department of Public \\ Health Medicine \\ N A Taub \\ Correspondence to: \\ Dr G F Watts \\ Accepted for publication \\ 9 September 1992
}

tein (LDL) cholesterol due to a combination of genetic and environmental factors that disturb the transport of apolipoprotein B-100 in plasma. ${ }^{4}$ Recent preventive strategies for $\mathrm{CHD}^{12}$ have resulted in common hypercho- lesterolaemia being the most frequent reason for referral to lipid clinics. ${ }^{5}$

Among patients with common hypercholesterolaemia CHD takes many forms and varies in degree of severity. ${ }^{3}$ This is probably due to genetic factors, and an important one may be the serum concentration of lipoprotein(a) ( $\mathrm{Lp}(\mathrm{a})),{ }^{6}$ as has been suggested in the less common disorder familial hypercholesterolaemia. ${ }^{78} \mathrm{Lp}(\mathrm{a})$ is structurally related to LDL and consists of a highly glycosylated subunit, apo(a), linked by disulphide bridges to the LDL particle. ${ }^{6}$ The serum concentration is chiefly under genetic control. ${ }^{9}$ Several studies have indicated that $\operatorname{Lp}(a)$ has both atherogenic and thrombogenic properties ${ }^{10-13}$; the latter is due to sequence homology with plasminogen ${ }^{14}$ and may be critical in increasing the risk of myocardial infarction (MI). ${ }^{15}$ There is dispute, however, as to whether the risk of $\mathrm{CHD}$ conferred by raised $\mathrm{Lp}(\mathrm{a})$ is independent of LDL or apolipoprotein B. ${ }^{15-17}$

\section{Methods}

Fifteen men with common hypercholesterolaemia who had sustained an MI within the previous two years were selected from consecutive referrals to the St Thomas's Hospital lipid clinic. Common hypercholesterolaemia was defined as: a serum concentration of LDL cholesterol between 3.5 and $7.2 \mathrm{mmol} / \mathrm{l}$ and a triglyceride of $<3.8 \mathrm{mmol} / \mathrm{l}$; together with absence of premature CHD (age 40 years or under), or tendon xanthomata in the index patient, or first or second degree relative; and a plasma cholesterol of $<8.0$ $\mathrm{mmol} / \mathrm{l}$ in all relatives screened for hyperlipidaemia. ${ }^{3} 1819$ These criteria were chosen with the intention of excluding familial hypercholesterolaemia and familial combined hyperlipidaemia. MI was defined according to well recognised plasma enzyme and electrocardiographic changes: serial increases in creatinine kinase, aspartate transaminase, and hydroxybutyric dehydrogenase activities, with or without an ST segment increase and development of $T$ wave inversion and $Q$ waves, for acute events. Where these data were not available, pathological $Q$ waves on the electrocardiogram was used as major criteria for the retrospective diagnosis of $\mathrm{MI} .^{20}$ Controls were selected consecutively from men without a previous history of MI who had been referred to the lipid clinic at the same time as the men with the primary diagnosis of common hypercholesterolaemia. Resting 12 lead ECGs were within normal limits in controls. 
Table 1 Clinical and demographic characteristics of the patients studied

\begin{tabular}{|c|c|c|c|}
\hline Characteristic & $\begin{array}{l}\text { With myocardial } \\
\text { infarction }\end{array}$ & $\begin{array}{l}\text { Without myocardial } \\
\text { infarction }\end{array}$ & $\begin{array}{l}p \text { Value } \\
\text { for difference }\end{array}$ \\
\hline $\begin{array}{l}\text { Number } \\
\text { Age (y) } \\
\text { Body mass index }\left(\mathrm{kg} / \mathrm{m}^{2}\right) \\
\text { Smoker/ex-smoker }(\%) \\
\text { Regular alcohol }(\%) \\
\text { Family history CHD (\%) } \\
\text { History of hypertension (\%) } \\
\text { Angina pectoris (\%) } \\
\text { Anti-anginal drugs (\%) } \\
\text { Systolic blood pressure } \\
\text { (mm Hg) }\end{array}$ & $\begin{array}{l}15 \\
52 \cdot 6(2 \cdot 0) \\
26 \cdot 0(0 \cdot 6) \\
87 \\
73 \\
20 \\
7 \\
86 \\
73 \\
128(2 \cdot 6)\end{array}$ & $\begin{array}{l}15 \\
51 \cdot 3(1 \cdot 7) \\
27 \cdot 2(0 \cdot 7) \\
93 \\
67 \\
27 \\
13 \\
53 \\
60 \\
130(2 \cdot 0)\end{array}$ & $\begin{array}{l}>0.1 \\
>0.1 \\
>0.1 \\
>0.1 \\
>0.1 \\
>0.1 \\
>0.1 \\
>0.1 \\
>0.1 \\
>0.1\end{array}$ \\
\hline $\begin{array}{l}\text { Diastolic blood pressure } \\
(\mathrm{mm} \mathrm{Hg})\end{array}$ & $83(1 \cdot 8)$ & $82(1 \cdot 3)$ & $>0.1$ \\
\hline
\end{tabular}

Mean (SEM) for continuous variables

Patients with secondary hypercholesterolaemia-for example, diabetes mellitus or hypothyroidism-or taking anti-lipaemic medication were excluded.

Details were taken of angina pectoris, medication, smoking habit, alcohol consumption, family history of CHD and personal history of hypertension. Body weight (kg), height (m) and arterial blood pressure (supine Korotkov V) were measured. Body mass index $\left(\mathrm{kg} / \mathrm{m}^{2}\right)$ was calculated. After a 12 hour fast venous blood was obtained (plain glass bottle) with minimal stasis and with the patient recumbent for serum lipid and lipoprotein analyses. All patients had been sustaining diet with no lipid restrictions. MI was confirmed from clinical records. $\mathrm{Lp}(\mathrm{a})$ was also measured in a group of healthy, middle aged men working in local government offices and known to be free of CHD and to have a "desirable" serum concentration of LDL cholesterol $(<3.5$ $\mathrm{mmol} / \mathrm{l}) .^{2}{ }^{19}$

\section{LABORATORY ANALYSES}

Serum cholesterol, triglyceride, and high density lipoprotein (HDL) cholesterol were assayed within four days of blood being taken. Enzyme kits were used to measure both cholesterol (Boehringer, Lewes, England) and triglycerides (Wako Chemicals, Neuss, Germany). HDL cholesterol was measured after precipitation of apolipoprotein lipo B with manganese chloride and heparin, excess manganese being chelated with $\mathrm{Na}_{2}$ EDTA before cholesterol assay. Aliquots of serum for apoprotein measurements were stored at $-70^{\circ} \mathrm{C}$ and thawed rapidly at $37^{\circ} \mathrm{C}$ immediately before analysis. Apolipoprotein AI (ApoAI) and apolipoprotein B (apoB) were measured using the method of Mount et $a l .{ }^{21} \mathrm{Lp}$ (a) was assayed by an immunoturbidimetric kit method (Immuno Ltd., Sevenoaks,

Table 2 Serum lipids, lipoproteins, and apolipoproteins in hypercholesterolaemic patients with and without $M I$

\begin{tabular}{|c|c|c|c|}
\hline $\begin{array}{l}\text { Lipids, lipoproteins, } \\
\text { and apolipoproteins }\end{array}$ & $\begin{array}{l}\text { With myocardial } \\
\text { infarction }(n=15)\end{array}$ & $\begin{array}{l}\text { Without myocardial } \\
\text { infarction }(n=15)\end{array}$ & $\begin{array}{l}p \text { Value } \\
\text { for difference }\end{array}$ \\
\hline $\begin{array}{l}\text { Cholesterol }(\mathrm{mmol} / \mathrm{l}) \\
\text { LDL cholesterol }(\mathrm{mmol} / \mathrm{l}) \\
\text { HDL cholesterol }(\mathrm{mmol} / \mathrm{l}) \\
\text { Triglyceride (mmol/l) } \\
\text { Apolipoprotein AI }(\mathrm{g} / \mathrm{l}) \\
\text { Apolipoprotein B }(\mathrm{g} / \mathrm{l}) \\
\text { Lipoprotein }(\mathrm{a})(\mathrm{g} / \mathrm{l}) \dagger \\
\text { LDL/HDL cholesterol } \\
\text { Apo B/Apo AI }\end{array}$ & $\begin{array}{l}7.02(0.23) \\
4.94(0.24) \\
1 \cdot 12(0.05) \\
2 \cdot 13(0.20) \\
1.26(0.05) \\
1.41(0.06) \\
0.64(0.36-1 \cdot 14) \\
4.57(0.32) \\
1 \cdot 15(0.07)\end{array}$ & $\begin{array}{l}6.89(0.15) \\
4.59(0.16) \\
1.17(0.08) \\
2.33(0.24) \\
1.38(0.05) \\
1.38(0.05) \\
0.30(0.21-0.42) \\
4.21(0.36) \\
1.03(0.07)\end{array}$ & $\begin{array}{l}>0.1 \\
>0.1 \\
>0.1 \\
>0.1 \\
>0.1 \\
>0.1 \\
=0.02 \\
>0.1 \\
>0.1\end{array}$ \\
\hline
\end{tabular}

$\star$ Values are mean (SEM); tgeometric mean ( $95 \%$ confidence interval)
England) (Kearney EM, et al. An indirect immunoturbidimetry assay for $\mathrm{Lp}(\mathrm{a})$. 55th Meeting of the European Atherosclerosis Society, May 1990). To prevent artefact due to a "matrix effect" standards and serum samples were diluted in phosphate buffered saline supplemented with $7 \%$ bovine serum albumin. ${ }^{22}$ Linear regression analysis showed a very good agreement between our immunoturbidimetric assay (IT) for $\mathrm{Lp}(\mathrm{a})$ and an enzyme linked immunosorbent assay (ELISA): IT $=0.76$ ELISA $+0.16 \mathrm{~g} / \mathrm{l} ; \mathrm{r}=$ $0 \cdot 88 ; n=80$. Interassay coefficients of variation for all methods were less than $3.5 \%$ at "high" and "low" control values. LDL cholesterol was calculated by the Friedewald formula. $^{23}$

\section{STATISTICAL METHODS}

Continuous variables were compared between the two groups of patients using the unpaired $t$ test, Lp(a) values being logarithmically transformed because of their positively skewed distribution. Discrete variables were compared by Fisher's exact test. Predictors of MI were examined using a forwards stepwise logistic regression analysis. The risk of $\mathrm{MI}$ associated with an $\mathrm{Lp}(\mathrm{a})$ of $>$ $0.57 \mathrm{~g} / \mathrm{l}$ compared with that associated with an $\mathrm{Lp}(\mathrm{a})$ of $\leqslant 0.57 \mathrm{~g} / \mathrm{1}^{8}$ was calculated as the odds ratio with $95 \%$ confidence interval ${ }^{24}$; the corresponding relative risk was also calculated assuming that $10 \%$ of the hypercholesterolaemic population without $\mathrm{CHD}$ has a serum $\mathrm{Lp}(\mathrm{a})$ of $>0.57 \mathrm{~g} / 1 .{ }^{25}$ The odds ratio was adjusted for age, smoking, mean arterial blood pressure and serum apoB using a multiple logistic method; specific adjustment for apoB was made because of evidence suggesting that it is a better predictor of $\mathrm{MI}$ than $\mathrm{Lp}(\mathrm{a}) .{ }^{17}$ The cutoff value of $0.57 \mathrm{~g} / 1$ for $\mathrm{Lp}(\mathrm{a})$ was chosen for these analyses because it had previously been shown to discriminate well between familial hypercholesterolaemic patients with and without MI. ${ }^{8}$

\section{Results}

Table 1 shows the clinical and demographic characteristics of the patients with and without MI. There were no statistically significant differences in the characteristics between the groups, but anginal symptoms and use of anti-anginal drugs were more common in the patients with $\mathrm{MI}$.

Table 2 shows the serum lipid, lipoprotein, and apolipoprotein concentrations in cases and controls. Hypercholesterolaemia was due to an increase in LDL cholesterol, consistent with polygenic or common hypercholesterolaemia. There were no significant group differences in serum cholesterol, LDL cholesterol, HDL cholesterol, triglyceride, apo AI, apo B, or in LDL:HDL cholesterol and apo B:apo AI ratios. The geometric mean of the serum concentration of $\mathrm{Lp}$ (a) was, however, twofold higher in the cases than in the controls $(p=0.02)$. The figure shows the serum concentrations of $\mathrm{Lp}(\mathrm{a})$ in the two groups of patients and in normocholestero- 


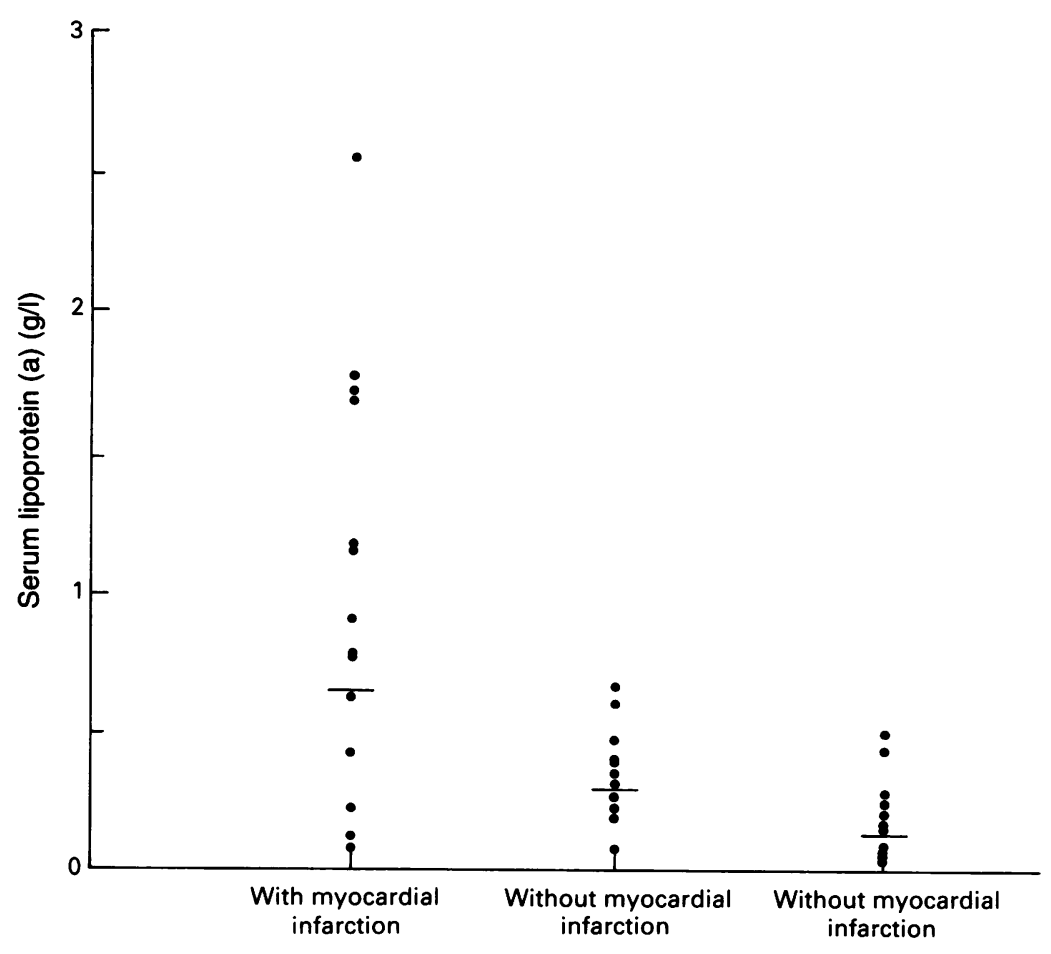

Hypercholesterolaemia Normocholesterolaemia Serum concentrations of lipoprotein (a) in hypercholesterolaemic patients with and without MI and in normocholesterolaemic subjects without MI. Bars are geometric means. $n=15$ in each group.
$\mathrm{Lp}(\mathrm{a})$ is a risk factor for MI. ${ }^{6}{ }^{15}$ The degree of independent risk attributed to $\mathrm{Lp}$ (a) has not, however, been formally tested in other casecontrol studies; $;^{15}$ nor have these focused on patients with common hypercholesterolaemia, the most common metabolic disorder seen in lipid clinics. Rhoads et al suggested that the odds ratio attributed to an increase in $\mathrm{Lp}(\mathrm{a})$ varied from 1.6 to 3.6 , the risk being higher in younger subjects. ${ }^{15}$ The greater odds ratio found in the present study might be due to use of a higher "cutoff" for Lp(a), a smaller sample size, or selection of patients for increased LDL cholesterol. As shown in familial hypercholesterolaemia risk of $\mathrm{CHD}$ attributed to $\mathrm{Lp}(\mathrm{a})$ may depend on the serum concentration of LDL cholesterol. ${ }^{78}$ Durrington et al, however, showed that in patients with hypercholesterolaemia a family history of premature CHD was as good a predictor of $\mathrm{MI}$ as apo(a), apoB being the best predictor of $\mathrm{MI}$ in discriminant analysis. ${ }^{17}$ Discrepancies between their study and ours may have been due to differences in study design, selection of patients, immunochemical assay for $\mathrm{Lp}(\mathrm{a})$ and accuracy of eliciting a family history of premature CHD.

That increased serum $\operatorname{Lp}(a)$ is part of the acute phase response to underlying atherosclerosis is highly improbable. ${ }^{26} \mathrm{Lp}(\mathrm{a})$ is well recognised to have both atherogenic and thrombogenic properties. $^{625}$ Increased susceptibility to arterial thrombosis may have as its basis the sequence homology of the apo(a) subunit with plasminogen. ${ }^{14}$ Inhibition of the binding of plasminogen to its activator site on vascular endothelium may explain why $L p(a)$ increased risk of $\mathrm{MI}$ in the present study. ${ }^{10}{ }^{11}$ Hypercholesterolaemia may also induce a procoagulant state by increasing platelet aggregation, factor VII coagulant activity, and plasma fibrinogen. ${ }^{25} 27$ The association between raised serum $L p(a)$ and these events is at present unclear.

The metabolic determinants of increased serum concentrations $\mathrm{Lp}(\mathrm{a})$ are unknown. $\mathrm{Lp}(\mathrm{a})$ is not affected by age, sex, diet or drugs that increase the catabolism of LDL apoB. ${ }^{625}$ By contrast, drugs that inhibit hepatic production of apoB tend to lower serum $\operatorname{Lp}(a){ }^{28}$ Accordingly, the plasma concentration of $\mathrm{Lp}(\mathrm{a})$ is determined by its rate of synthesis rather than its rate of catabolism. ${ }^{29}{ }^{30}$ Given the significant differences in $\operatorname{Lp}(a)$ between hypercholesterolaemic patients and normocholesterolaemic subjects found in the present study, it is possible that a transport defect of apoB might have accounted for increased concentrations. This would entail differences in hepatic production of $\mathrm{apoB}$ and we cannot entirely exclude a greater prevalence of familial combined hyperlipidaemia in our patients with MI. As indicated elsewhere, ${ }^{3}$ it is more likely that genetic factors accounted for the differences in $\mathrm{Lp}(\mathrm{a})$ between patient groups ${ }^{7}$; patients with MI may, for example, have a preponderance of the $\mathrm{Lps}^{1}$ and $\mathrm{Lps}^{2}$ alleles, size polymorphisms that code for higher serum $\mathrm{Lp}$ (a) concentrations. ${ }^{9}$ 
We conclude that measurement of serum $\mathrm{Lp}$ (a) may allow clinicians to identify patients with common hypercholesterolaemia at increased risk of MI. Focusing management on patients with the worst cardiovascular prognosis will optimise use of resources in lipid clinics. Increased $\mathrm{Lp}(\mathrm{a})$ concentrations may potentially be treated with $\omega$ 3-fatty acids, niacin, statins or neomycin, but the efficacy of these treatments is still controversial $^{31}$; conventional fat modified diets do not seem to lower $\operatorname{Lp}(a) .^{32}$ Whether a reduction in raised plasma $\mathrm{Lp}(\mathrm{a})$ benefits the course of $\mathrm{CHD}$ and mitigates the risk of $\mathrm{MI}$ also needs to be proved. Moreover, development of agents specifically targeted at $\mathrm{Lp}(\mathrm{a})$ are awaited. ${ }^{31}$ In the interim, measurement of $L p(a)$ in patients attending lipid clinics instead may be regarded as useful in indicating to clinicians the need for intensive treatment for other cardiovascular risk factors other than $\mathrm{Lp}(\mathrm{a})$ per se. ${ }^{28}$

We thank $\mathrm{Mr} \mathrm{W}$ Jefferson for typing the manuscript.

1 Study Group, European Atherosclerosis Society. Strategies for the prevention of coronary heart disease: a policy statement from the European Atherosclerosis policy statement from the Europea

2 Shepherd J, Betteridge DJ, Durrington P, et al. Strategies for reducing coronary heart disease and desirable limits for blood lipid concentrations: guidelines of the British Hyperlipidaemia Association. $\mathrm{Br}$ Med $\mathcal{f}$ 1987;295: 1245-6.

3 Durrington PN. Common hypercholesterolaemia: polygenic hypercholesterolaemia and familial combined
hyperlipidaemia. In: Hyperlipidaemia. Diagnosis and management. London: PA Wright, 1989:114-34.

4 International Collaborative Study Group. Metabolic epidemiology of plasma cholesterol. Mechanisms of variation of plasma cholesterol within populations and vetween populations. Lancet 1986;ii:991-5.

5 Evans GR, Taylor G, Taylor KG. The work of a lipid clinic: an audit of performance. $Q \mathcal{F}$ Med 1990;74: 239-45.

6 Mbewu AD, Durrington PN. Lipoprotein (a): structure, properties and possible involvement in thrombogenesis and atherogenesis. Atherosclerosis 1990;85:1-14.

7 Wiklund O, Angelin B, Olofsson SO, et al. Apolipoprotein (a) and ischaemic heart disease in familial hypercholesterolaemia. Lancet 1990;335:1360-3.

8 Seed M, Hoppichler F, Reaveley D, et al. Relation of serum lipoprotein (a) concentration and apolipoprotein (a) phenotype to coronary heart disease in patients with familial hypercholesterolaemia. $N$ Engl f Med 1990;322: 1494-9.

9 Utermann G, Menzel HJ, Kraft HG, Duba HC, Kemmler HG, Seitz C. Lp(a) glycoprotein phenotypes: inheritance and relation to $\mathrm{Lp}(\mathrm{a})$-lipoprotein concentration in plasma. $\mathcal{F}$ Clin Invest 1987;80:458-65.

10 Miles LA, Fless GM, Levin EG, Scanu AM, Plow EF. A potential basis for the thrombotic risks associated with lipoprotein (a). Nature 1989;339:301-3.
11 Hajjar KA, Garish D, Breslow JL, Nachman RL. Lipoprotein (a) modulation of endothelial cell surface fibrinolysis and its potential role in atherosclerosis. Nature 1989;339:303-5.

12 Dahlen GH, Guyton JR, Attar M, Farmer JA, Krantz JA, Gotto AM. Association of levels of lipoprotein $\operatorname{Lp}(\mathrm{a})$, plasma lipids and other lipoproteins with coronary artery disease documented by angiography. Circulation 1986;74:758-63.

13 Rath M, Niendorf A, Reblin T, Dietel M, Krebber H-J, Beisiegel U. Detection and quantification of lipoprotein (a) in the arterial wall of 107 coronary bypass patients. Arteriosclerosis 1988;9:579-92

14 McLean JW, Tomlinson JE, Kuang W-J, et al. cDNA sequence of human apolipoprotein (a) is homologous to plasminogen. Nature 1987;330:132-7.

15 Rhoads GG, Dahlen G, Berg K, Morton NE, Dannenberg $\mathrm{AL}$. $\mathrm{Lp}(\mathrm{a})$ lipoprotein as a risk factor for myocardial infarction. $\mathcal{F} A M A 1986 ; 256: 2540-24$

16 Armstrong VW, Cremer P, Eberle E, et al. The association between serum $\mathrm{Lp}(\mathrm{a})$ concentrations and angiographically assessed coronary atherosclerosis. Atherosclerosis 1986;62:249-57.

17 Durrington PN, Ishola M, Hunt L, Arrol S, Bhatnagar D. Apolipoproteins (a), AI and B and parental history in men with early onset ischaemic heart disease. Lancet 1988;i:1070-3.

18 Durrington PN. Normal serum lipid and lipoprotein concentrations. In: Hyperlipidaemia. diagnosis and manconcentrations. In: Hyperlipidaemia. diagnosis

19 Hazzard WL, Goldstein JL, Schrott HG, Motulsky A, Bierman EL. Hyperlipidaemia in coronary heart disease. III. Evaluation of lipoprotein phenotypes in 156 genetically defined survivors of myocardial infarction. $\mathcal{F}$ Clin Invest 1973;52:1569-77.

20 Petch MC. Myocardial Infarction. In: Julian DG, Camm AJ, Fox KM, Hall RJC, Poole-Wilson PA Eds. Diseases of the heart. London: Ballière Tindall, 1989:1157-91.

21 Mount JN, Kearney EM, Rosseneu M, Slavin BM. Immunoturbidimetric assays for serum apolipoproteins $\mathrm{AI}$ and $\mathrm{B}$ using Cobas Bio centrifugal analyser. $\mathcal{F}$ Clin Pathol 1988;41:471-4.

22 Mackness MI. Report on the Lp(a) WorkshipManchester. Commun Lab Med 1992;2:499-502.

23 Friedewald WT, Levy RI, Frederickson DS. Estimation of the concentration of low-density lipoprotein cholesterol in plasma, without use of the preparative ultracentrifuge. Clin Chem 1972;18:499-502.

24 Altman DG. Practical statistics for medical research. London: Chapman \& Hall, 1991;266-70.

25 Beisiegel U. Lp(a): a new risk factor? Lipid Review 1989;3:73-6.

26 Sandholzer C, Boerwinkle E, Saha N, Tong MC Ultermann G. Apolipoprotein (a) phenotypes, Lp(a) concentrations and plasma lipid levels in relation to concentrations and plasma lipid levels in relation to dence for the role of the apo(a) gene in coronary heart dence for the role of the apo(a) gene
disease. $\mathcal{F}$ Clin Invest 1992;89:1040-6.

27 Gasser JA, Betteridge DJ. Lipids and thrombosis. Clin Endocrinol Metab 1990;4:923-38.

28 Scott J. Lipoprotein (a). Thrombogenic and atherogenic. BMF 1991;303:663-4

29 Knight BL, Perombelon YFN, Soutar AK, Wade DP Seed $M$. Catabolism of lipoprotein (a) in familial hypercholesterolaemic subjects. Atherosclerosis 1991;87: 277-33.

30 Perombelon YFN, Gallagher JJ, Myant NB, Soutar AK, Knight BL. Lipoprotein (a) in subjects with familial defective apolipoprotein B-100. Atherosclerosis 1992;92: 203-12.

31 Scanu AM, Fless GM. Lipoprotein (a). Heterogeneity and biological relevance. $\mathcal{F}$ Clin Invest 1990;85:1709-15. 32 Brown SA, Morrisett J, Patsch JR, Reeves R, Gotto AM Patsch W. Influence of short term dietary cholesterol and fat on human plasma $\operatorname{Lp}(a)$ and $\mathrm{LDL}$ levels. $₹$ Lipid Res 1991;32:1981-9. 